\title{
Effects of grazer diversity on marine microphytobenthic biofilm: a 'tug of war' between complementarity and competition
}

\author{
Carlos Sanz-Lázaro ${ }^{1,2, *}$, Luca Rindi ${ }^{1}$, Elena Maggi ${ }^{1}$, Martina Dal Bello ${ }^{1}$, \\ Lisandro Benedetti-Cecchi ${ }^{1}$ \\ ${ }^{1}$ Department of Biology, University of Pisa, CoNISMa, Via Derna 1, Pisa, Italy \\ ${ }^{2}$ Present address: Departamento de Ciencias del Mar y Biología Aplicada, Universidad de Alicante, PO Box 99, \\ 03080 Alicante, Spain
}

\begin{abstract}
Species loss is one of the most striking problems related to human-driven environmental changes. Nevertheless, biodiversity and ecosystem functioning experiments have mainly focused on primary producers, paying less attention to the consequences of changing diversity at higher trophic levels. We performed a field experiment using cage enclosures to test the effects of species richness, identity and density of gastropod grazers on the photosynthetic efficiency and biomass of intertidal biofilm on an exposed rocky shore in the northwest Mediterranean. The diversity and composition of intertidal grazers affected the photosynthetic efficiency of biofilm with only negligible effects on biomass. Individual species showed strong identity effects. In assemblages of 2 or more species, positive or negative complementarity effects occurred. The magnitude of the ecosystem response is expected to depend on the particular species assemblage and its density, which will determine whether niche partitioning or competition is the prevailing process. Grazer preference in specific components of biofilm, characterized by different photosynthetic efficiency and competitive abilities, might explain concomitant changes in photosynthetic efficiency and comparable levels in biomass among treatments. The effects of grazers declined following the natural trend of decreasing biomass of biofilm during the study period, highlighting the importance of considering temporal variability in the effects of biodiversity on ecosystem functioning. This work emphasizes the key role of species identity to predict effects on their resources and ecosystem functioning.
\end{abstract}

KEY WORDS: Biodiversity and ecosystem functioning $\cdot$ Density-dependent effects $\cdot$ Intertidal · Limpet $\cdot$ Patella sp. · Photosynthetic efficiency $\cdot$ Temporal heterogeneity $\cdot$ Topshell

\section{INTRODUCTION}

Biodiversity is one of the principal drivers of ecosystem processes, which, in turn, provide services for human well-being (Millennium Ecosystem Assessment 2005). Species loss can alter ecosystem functioning at a magnitude comparable to that of other important human-driven environmental changes, such as climate warming or eutrophication (Hooper et al. 2012). The high rate of species loss observed in recent decades (Butchart et al. 2010) has urged researchers to better understand the links between biodiversity and ecosystem functioning (BEF).

Initially, BEF experiments were mainly performed with synthesized assemblages of plants from grassland communities (Hector et al. 1999). In general, these experiments indicated that more diverse communities exhibited high productivity and a more efficient resource use compared to less diverse communities (Hooper et al. 2005). Later, BEF experiments 
were extended to other communities and their complexity has increased to better discriminate the effects of individual species (identity effects) from the effects of partitioning in resource use among species (complementarity) (Gable et al. 2012). Novel aspects of BEF research have also involved the analysis of realistic non-random species losses (Bracken et al. 2008) and the exploration of trophic interactions (Aquilino \& Stachowicz 2012). The inclusion of consumers in BEF studies was particularly important because trophic interactions can mediate the effects of changing richness of primary producers on ecosystem functioning and because higher trophic levels have greater extinction probabilities than basal levels (Purvis et al. 2000). While increasing diversity of primary producers is expected to increase primary production and thus biomass of plant organisms (Hooper et al. 2005), increasing diversity of consumers is expected to lead to a greater efficiency in consumption, and thus a greater impact on primary producers (e.g. biomass) (Duffy et al. 2001).

Marine ecologists have contributed to BEF research mostly in the last decade (Stachowicz et al. 2007, Bracken et al. 2008, Solan et al. 2012), partially because manipulation of species richness in the field is not as easy as in terrestrial grasslands. Nonetheless, in situ experimental manipulations can be performed quite easily in the rocky intertidal in comparison to other marine habitats (e.g. subtidal or pelagic systems). Rocky seashores are characterized by sessile or sedentary species, most of which are small in size, have short life spans and are distributed across steep physical gradients (Raffaelli \& Hawkins 1996). These characteristics make rocky intertidal assemblages ideal model systems in which to perform BEF experiments under natural conditions, and rocky intertidal studies have contributed substantially to our understanding of BEF in the marine environment (O'Connor \& Crowe 2005, Benedetti-Cecchi 2006, Stachowicz et al. 2007, Gamfeldt et al. 2015).

Gastropod grazers are key species in rocky intertidal habitats due to their role in structuring communities and influencing biodiversity and, thus, ecosystem processes (Raffaelli \& Hawkins 1996). Rocky intertidal assemblages are threatened by anthropogenic pressures (Helmuth et al. 2006), and molluscs appear particularly vulnerable to threats originating from human activities (Coll et al. 2010). In particular, pollution (Atalah \& Crowe 2012), harvesting (Thompson et al. 2002) and climate change (Hawkins et al. 2009) are likely to cause local extinctions of resident species of intertidal gastropods or the introduction of new ones, the effects of which on ecosystems processes are not yet fully understood (O'Connor \& Crowe 2005).

Past BEF field experiments examining the effect of grazing on primary producers in rocky intertidal systems have focused mostly on macroalgae, showing variable effects on producer biomass $\left(\mathrm{O}^{\prime} \mathrm{Connor} \&\right.$ Crowe 2005, Griffin et al. 2010). In contrast, a clear understanding of how loss of grazer diversity affects biofilm-forming microphytobenthos (hereafter we use the term 'biofilm' to refer to this autotrophic component) has remained elusive (but see Matthiessen et al. 2007), in spite of the wide ecological literature on the overall impact of grazing in these assemblages (e.g. Underwood 1984, Thompson et al. 2000). Biofilm on intertidal rocky shores is mainly composed of cyanobacteria, diatoms and macroalgal germlings, which are essential for the settlement of algal propagules and invertebrate larvae (Wahl 1989) and the functioning of intertidal systems (Thompson et al. 2004). Biofilm provides the major fraction of biomass produced and directly consumed in situ on rocky shores, prevalently by gastropods (Castenholz 1961, Thompson et al. 2000). Recent studies on rocky shore biofilm have mainly focused on its photosynthetic biomass (Matthiessen et al. 2007, Christofoletti et al. 2011). Nevertheless, physiological variables, such as photosynthetic efficiency, might add important information on the metabolic activity of primary producers (Bracken \& Williams 2013, Golléty \& Crowe 2013).

In this study we examined the effects of species richness, identity and density of 3 gastropod grazers (Patella ulyssiponensis, Patella rustica and Porchus turbinatus) inhabiting intertidal rocky shores in the northwestern Mediterranean on biofilm photosynthetic efficiency and biomass. These gastropod species differ in their diet composition and/or feeding behavior. Patella ulyssiponensis is a generalist herbivore (Della Santina et al. 1993), while P. rustica mostly feeds on cyanobacteria (Della Santina et al. 1993). In contrast to these slow-moving limpets, the topshell $P$. turbinatus is an active and highly mobile herbivore, feeding on diatoms, filamentous and unicellular algae, as well as detritus (Alyakrinskaya 2010). Importantly, taxa composing biofilm display different physiological (e.g. photosynthetic) and ecological traits. For example, cyanobacteria are characterized by a lower photosynthetic efficiency in comparison to diatoms or green algae (Kaehler \& Froneman 2002, Bonnineau et al. 2010), but are competitively dominant over the other taxa (Norton et al. 1990, Kaehler \& Froneman 2002). We hypothesize that identity of grazers can play a key role in both 
biofilm photosynthetic biomass and efficiency, due to differences in consumption rates and diets among manipulated species; this effect may change with density, due to intra- or interspecific competition. In fact, identity effects could be responsible for nonlinear effects such as those observed at increasing richness of grazers, depending on the relative importance of resource partitioning (i.e. complementary effect) versus density-dependent mechanisms of intraor interspecific competition within a particular assemblage composition. To test these hypotheses we performed a manipulative field experiment using cage enclosures and measured in situ fluorescence of the microphytobenthic biofilm to estimate changes in photosynthetic biomass and efficiency of these microscopic primary producers through time.

\section{MATERIALS AND METHODS}

\section{Study site}

The experiment was carried out at Calafuria, a sandstone rocky shore located in the Ligurian Sea,

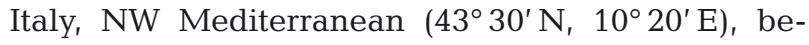
tween 0.1 and $0.3 \mathrm{~m}$ above the mean low-water level. At this height on the shore, the dominant macroorganisms are the red alga Rissoella verruculosa and barnacles (Chthamalus stellatus and C. montagui), along with other erect (Nemalion helminthoides and Polysiphonia sertularioides) and encrusting (e.g. Ralfsia verrucosa) algae and colonial cyanobacteria (Rivularia spp.) (Benedetti-Cecchi 2000). This assemblage is representative of exposed mid-shore habitats of rocky shores in the northwestern Mediterranean. Gaps within erect organisms are common in these assemblages and are generally occupied by a thin layer of biofilm. Biofilm assemblages at the study site show a scale-invariant spatial distribution, likely determined by the superimposition of several processes acting at different spatial scales, among which grazing by intertidal gastropods is prominent (Dal Bello et al. 2015). The most common grazers are the topshell Porchus turbinatus and the limpets Patella ulyssiponensis and Patella rustica.

\section{Experimental design}

In January 2012, 56 plots $(15 \times 15 \mathrm{~cm})$, were marked with epoxy putty (Subcoat S, Veneziani) in areas with no macroalgae, along approximately $1 \mathrm{~km}$ of shoreline. Four plots were left untouched and used as controls, while the remaining 52 plots were randomly allocated to 12 experimental treatments consisting of different combinations of species richness, identity and density of the 3 most common macrograzers present in the area (i.e. $P$. turbinatus, $\mathrm{PT}_{;} P$. ulyssiponensis, $\mathrm{PU}$; and $P$. rustica, PR). Species richness had 4 levels, consisting of experimental plots with 0 (exclusion), 1 (PT, PU or PR), 2 (PT+PU, PT+PR, $\mathrm{PU}+\mathrm{PR})$ or 3 (PT+PU+PR) species. Treatments with 1 and 3 species were crossed with 2 density levels. To reflect a realistic range of grazer abundance, as previously documented in the study area, the high density (HD) treatment was set to 6 individuals per plot and the low density (LD) treatment to 3 individuals per plot (see Table S1 in the Supplement at www. int-res.com/articles/suppl/m540p145_supp.pdf). As a consequence, it was not possible to include a 2 species treatment at low density. Including grazer density as a factor in the experiment enabled us to disentangle richness from density-dependent effects (Benedetti-Cecchi 2004). Each treatment had 4 replicates. To prevent escape (or entrance) of grazers, we used cages $(15 \times 15 \times 4 \mathrm{~cm}$ length, width and height, respectively) with $12 \mathrm{~mm}$ mesh size, which allowed water flow. Cages were made of metal covered with plastic to prevent corrosion and reinforced with a galvanized mesh $(6 \mathrm{~mm})$ to resist wave impact. To check for possible artefacts due to the presence of the cages, an additional treatment was included (control for artefacts, CA), consisting of cages with openings that enabled the access of grazers.

Cages were attached to the rock with stainless steel screws placed into plugs in the rock. Grazers were taken from the surrounding area, selecting individuals with shell diameters of 9-13 mm for P. turbinatus, and 11-15 $\mathrm{mm}$ for $P$. ulyssiponensis and P. rustica. These sizes correspond to adult individuals that are commonly found on the shore. Grazers were relocated into the experimental plots very carefully. Individuals were taken with blunt metal sheets to avoid breaking the shell and immediately placed in their corresponding plot, where they were gently held against the rock for some minutes to facilitate attachment. After 1 to $2 \mathrm{~h}$ we checked whether grazers were still attached to the rock, which was generally the case. If grazers were missing, they were replaced with new individuals. The experiment ran for $70 \mathrm{~d}$, and cages were checked every 7 to $10 \mathrm{~d}$. Occasionally missing individuals were replaced by new ones. We also verified that all manipulated species had access to the control and CA treatments. Because cages can attract grazers, we also checked that CA did not have unusually high abundances of grazers. 


\section{Sampling}

Sampling was performed between January and March 2012, 36, 58 and $69 \mathrm{~d}$ from the setup of the experiment. At each time, in vivo fluorescence of biofilm was measured through a portable underwater pulse-amplitude-modulated (PAM) fluorometer (Diving-PAM, Walz). This is a non-destructive method to obtain real-time measures of the physiological status and biomass of the photosynthetic components of the biofilm. The probe measured an area of approximately $24 \mathrm{~mm}^{2}$. Effective quantum yield of photosystem II $\left(\Delta F / F_{\mathrm{m}}{ }^{\prime}\right)$ and minimum fluorescence after dark adaptation $\left(F_{0}\right)$ were measured and used as surrogates of the photosynthetic efficiency and the photosynthetic biomass of biofilm, respectively (Schreiber 2004). The effective quantum yield of photosystem II is described as follows:

$$
\Delta F / F_{\mathrm{m}}{ }^{\prime}=\frac{F_{\mathrm{m}}{ }^{\prime}-F^{\prime}}{F_{\mathrm{m}}{ }^{\prime}}
$$

where $\Delta F$ corresponds to the increase in fluorescence yield, induced by a saturating light pulse on light-adapted samples; $F_{\mathrm{m}}$ ' is the maximal fluorescence yield of light-adapted samples induced by a saturating light pulse; and $F^{\prime}$ is the fluorescence yield under light-adapted conditions (i.e. with some photosystem II centers closed), measured before application of a saturating light pulse. Thus, $\Delta F / F_{\mathrm{m}}{ }^{\prime}$ is the effective quantum efficiency of photosystem II (ФPSII) of open photosystem II centers in the light, estimating the effective photosynthetic efficiency of the sample. $F_{0}$ corresponds to the minimal fluorescence yield when the sample is dark adapted (i.e. with all photosystem II centres open). Several studies have proved a relationship between minimum fluorescence yield and microphytobenthos biomass (Barranguet \& Kromkamp 2000, Honeywill et al. 2002). At our study site we obtained the following linear regression: chl a concentration $\left.(\mu \mathrm{g} \mathrm{cm})^{-2}\right)=0.226+0.003 \cdot F_{0}\left(\mathrm{R}^{2}=0.64 ; \mathrm{p}<0.001\right.$; $\mathrm{n}=51$ ).

At each sampling time and within each replicate, 3 measurements were randomly taken for both $\Delta F / F_{\mathrm{m}}{ }^{\prime}$ and $F_{0}$, avoiding areas close to the margins of the cage (approximately $2 \mathrm{~cm}$ from the border), to prevent possible border effects. The average of the 3 measurements was then calculated and used as the value for each replicate. We started taking measurements approximately $2.5 \mathrm{~h}$ after sunrise and stopped around midday. Weather conditions were similar at the 3 sampling dates. Values of photosynthetically active radiation (PAR) were similar among treat- ments and sampling dates (data not shown). We wet the rock surface with seawater 5 min before taking the measurements (Maggi et al. 2013) and kept the distance and the angle between the sensor of the PAM fluorometer and the rock surface constant (Logan et al. 2007) through the use of a holder, in order to obtain comparable values.

The $\Delta F / F_{\mathrm{m}}{ }^{\prime}$ measurements were taken in the light, avoiding shading by the equipment or the researcher. $F_{0}$ measurements were previously dark adapted for 5 min with modified dark leaf clips. A 5 min period is considered long enough to avoid nonphotochemical quenching, as well as not too long to activate other processes, such as the maintenance of the trans-thylakoid proton gradient. Both processes can alter the value of $F_{0}$ (Jesus et al. 2006).

\section{Data analyses}

We used mixed effects models to examine the effects of species richness, identity and density of $P$. turbinatus, P. ulyssiponensis and P. rustica on biofilm and to model temporally autocorrelated observations within experimental plots. We started by fitting models with restricted maximum likelihood (REML), and examined whether residuals conformed to parametric assumptions through quantile-quantile plots and plots of residuals versus fitted values (Singer \& Willet 2003). Then, we refitted the models with maximum likelihood (ML) to estimate fixed parameters. Time was included as a covariate in the fixed part of the model to assess treatment effects on temporal trajectories and in the random part of the model to account for variations in these trajectories among experimental plots.

A first analysis included all HD treatments and tested for the effects of species richness on photosynthetic biomass and efficiency of biofilm. Richness was used as a continuous covariate in this analysis in order to evaluate the response of $F_{0}$ and $\Delta F / F_{\mathrm{m}}{ }^{\prime}$ along a gradient of species richness (Hector et al. 1999, Emmerson \& Huxham 2002). We included the exclusion treatment as the ' 0 ' level. Preliminary inspection of the data suggested nonlinear relationships between the response variable and richness, which we modelled through cubic polynomials.

A second set of analyses included all the treatments with 1 and 3 species at both levels of density. A set of a priori contrasts were planned to test for the effects of species richness (implemented as a categorical variable with 1 versus 3 species), species identity (limpets versus topshell: [PU+PR] versus $\mathrm{PT}_{\text {; }}$ 
and between the 2 species of limpets: PU versus PR) and the interaction between these contrasts and density.

The results of these analyses were plotted as fitted means \pm bootstrapped SDs obtained by 1000 iterations. When showing all the sampling times, plots also display the temporal linear prototypical trajectories.

To check for potential artefacts due to the presence of cages, we performed an analysis contrasting control and CA plots. Additionally, we compared control plots and those with 3 species to assess how well our HD treatment mimicked natural conditions with respect to values of biofilm photosynthetic efficiency and biomass.

We compared the photosynthetic efficiency and biomass of biofilm between species mixture treatments with the average value of each of these variables calculated across single species treatments (corresponding to non-transgressive over/underyielding in biodiversity experiments with plants, $D_{\mathrm{T}}$ ) and with the best performing single species treatment (corresponding to transgressive over/underyielding, $D_{\mathrm{MAX}}$ ) (Loreau \& Hector 2001). We ran these analyses separately for each sampling date. We used the partitioning method proposed by Loreau (1998) for these comparisons:

$$
D_{T}=\frac{O-\bar{E}}{\bar{E}}
$$

where $O$ is the observed yield (photosynthetic activity or biomass of biofilm) in treatments with more than one species of grazer and $\bar{E}$ is the expected yield in species mixtures based on yields from treatments with one species of grazer;

Table 1. Summary of the effects of gastropod species richness on photosynthetic efficiency $\left(\Delta F / F_{\mathrm{m}}{ }^{\prime}\right)$ and photosynthetic biomass $\left(F_{0}\right)$. Significant effects are indicated in bold

\begin{tabular}{|c|c|c|c|c|}
\hline & \multicolumn{2}{|c|}{ Mean at first sampling date } & \multicolumn{2}{|c|}{ Temporal trends } \\
\hline & Coefficient $( \pm \mathrm{SE})$ & $\mathrm{p}$ & Coefficient $( \pm \mathrm{SE})$ & $\mathrm{p}$ \\
\hline \multicolumn{5}{|l|}{$\Delta F / F_{\mathrm{m}}^{\prime}$} \\
\hline Intercept & $0.151 \pm 0.056$ & 0.009 & $0.0005 \pm 0.0025$ & 0.837 \\
\hline Richness linear & $-0.309 \pm 0.122$ & 0.017 & $0.0062 \pm 0.0058$ & 0.286 \\
\hline Richness quadratic & ic $\quad 0.241 \pm 0.089$ & 0.012 & $-0.0047 \pm 0.0044$ & 0.282 \\
\hline Richness cubic & $-0.051 \pm 0.019$ & 0.012 & $0.001 \pm 0.0009$ & 0.288 \\
\hline \multicolumn{5}{|l|}{$F_{0}$} \\
\hline Intercept & $534.1 \pm 131.7$ & 0.000 & $-11.16 \pm 4.05$ & 0.008 \\
\hline Richness linear & $-693.8 \pm 354$ & 0.060 & $17.71 \pm 10.88$ & 0.109 \\
\hline Richness quadratic & ic $497.8 \pm 284.6$ & 0.091 & $-14.14 \pm 8.74$ & 0.111 \\
\hline Richness cubic & $-98.35 \pm 62.1$ & 0.125 & $3.09 \pm 1.91$ & 0.111 \\
\hline
\end{tabular}

$$
D_{\mathrm{MAX}}=\frac{O-E_{\mathrm{MAX}}}{E_{\mathrm{MAX}}}
$$

with $O$ defined as before and $E_{\mathrm{MAX}}$ reflecting biofilm yield in the best performing single species treatment, i.e. the treatment with the lowest values of biofilm biomass (or photosynthetic efficiency) among those with one species of grazer. We repeated these calculations for each level of grazer density separately. Note that because we were examining the impact of grazing on biofilm, the interpretation of $D_{\mathrm{T}}$ and $D_{\mathrm{MAX}}$ proceeds in the opposite direction compared to what is commonly done in plant biodiversity experiments (Loreau 1998). For example, complementary effects among grazers would result in lower values of biofilm biomass in mixtures than in single species treatments, resulting in negative values of $D_{\mathrm{T}}$ and $D_{\mathrm{MAX}}$.

These effects were evaluated with one-way ANOVAs comparing mixtures with single species treatments for each level of density separately. Cochran's C-test was used to check homogeneity of variances and, if needed, a $\ln (x+1)$ transformation was applied to remove heterogeneity (Underwood 1997).

Analyses were run in R (v. 2.15.0) and mixed models were implemented using the lme function in the statistical package nlme (v. 3.1-103) (R Development Core Team 2012).

\section{RESULTS}

Biofilm photosynthetic efficiency was nonlinearly related to gastropod species richness at the first sampling date (Fig. 1A,C, Table 1). Excluding grazers resulted in the highest values of the response variable, followed by treatments with 2, 1 and 3 species present. In contrast, species richness had no significant effect on biofilm photosynthetic biomass, although there was a linear trend, at the first sampling date, suggesting a negative response of this variable to increasing levels of richness (Fig. 1B,D, Table 1).

In general, differences between treatments declined through time for both response variables independently of variation in species richness (Table 1, Fig. 1A,B). While photosynthetic efficiency generally increased during the course of the experiment, biofilm biomass decreased, particularly in the 
grazer exclusion treatment (see the significant intercept for the linear effect of time in Table 1). There were no significant effects between richness treatments with 1 and 3 species and their interaction with density on either response variable (see Table $\mathrm{S} 2$ in the Supplement).
Grazing limpets had differential effects on biofilm photosynthetic activity. A significant identity effect was evident at the first sampling date, with plots containing Patella ulyssiponensis showing lower values of biofilm photosynthetic efficiency than those with Patella rustica (Figs. $2 \& 3$; see Table S2 in the
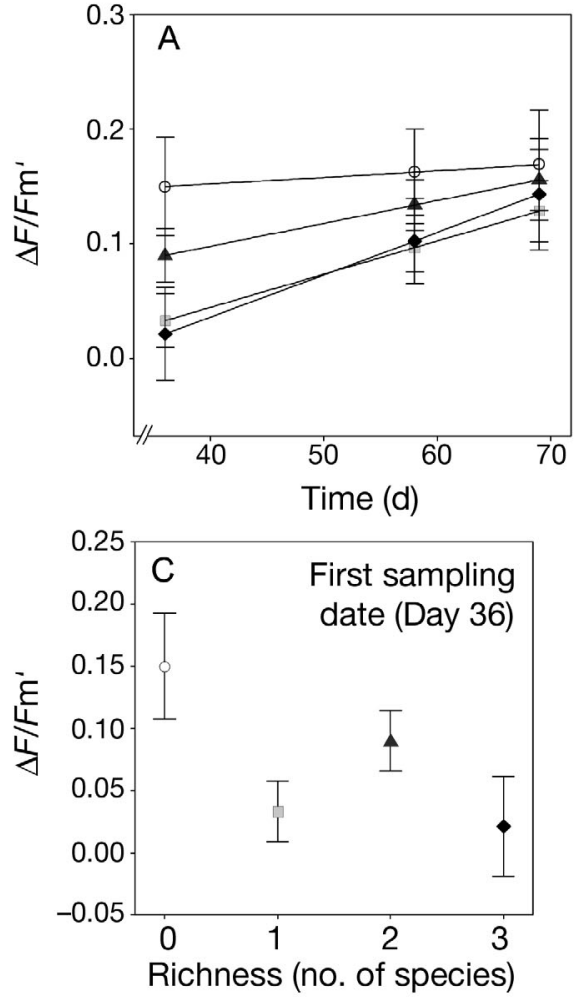
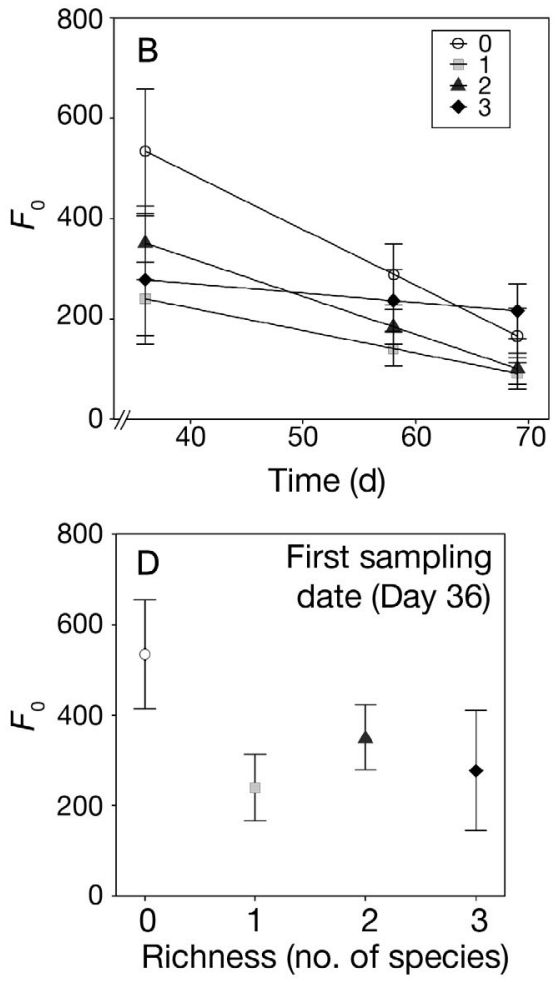

Fig. 1. Effects of species richness on $(\mathrm{A}, \mathrm{C})$ photosynthetic efficiency $\left(\Delta F / F_{\mathrm{m}}{ }^{\prime}\right)$ and $(\mathrm{B}, \mathrm{D})$ photosynthetic biomass $\left(F_{0}\right)$. In $A$ and $B$, the lines show the prototypical trajectories of the temporal trends of these parameters, while C and D focus on the first sampling date, Day 36 ( $\mathrm{n}=4$ replicates per treatment, fitted means \pm bootstrapped standard deviations obtained by 1000 iterations). 0 species corresponds to the exclusion treatment. All treatments with species correspond to the high density level (i.e. 6 individuals per plot): 1 species, all single-species treatments (Patella ulyssiponensis [PA], Patella rustica [PR] and Porchus turbinatus [PT]); 2 species, treatments with all possible combinations of 2 species $(\mathrm{PA}+\mathrm{PR}, \mathrm{PA}+\mathrm{PT}$ and $\mathrm{PR}+\mathrm{PT})$; and 3 species, treatment with all 3 species together $(\mathrm{PA}+\mathrm{PR}+\mathrm{PT})$
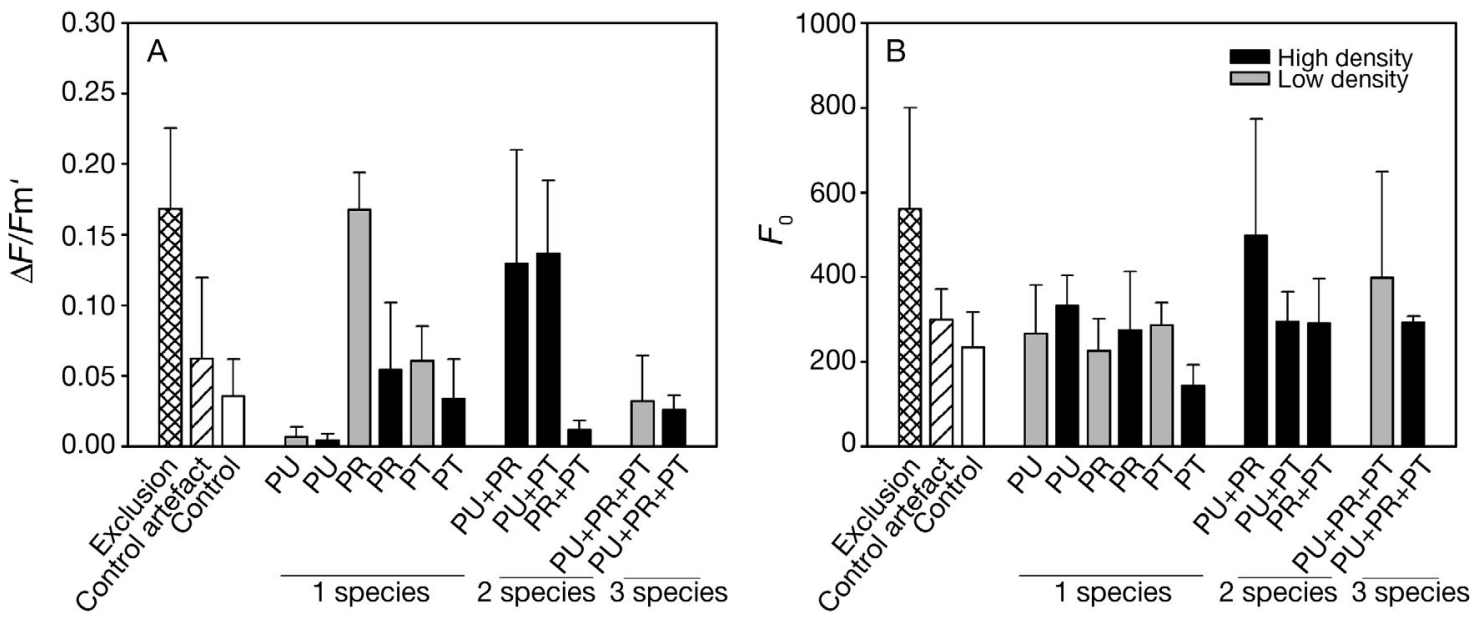

Fig. 2. Effects of species richness, identity and density on $(\mathrm{A})$ photosynthetic efficiency $\left(\Delta F / F_{\mathrm{m}}{ }^{\prime}\right)$ and (B) photosynthetic biomass $\left(F_{0}\right)$ for the first sampling date. PU, PR and PT stand for treatments with Patella ulyssiponensis, Patella rustica and Porchus turbinatus, respectively. The levels of high and low density correspond to 6 and 3 animals per plot, respectively (n = 4 , means $\pm \mathrm{SE}$ ) 


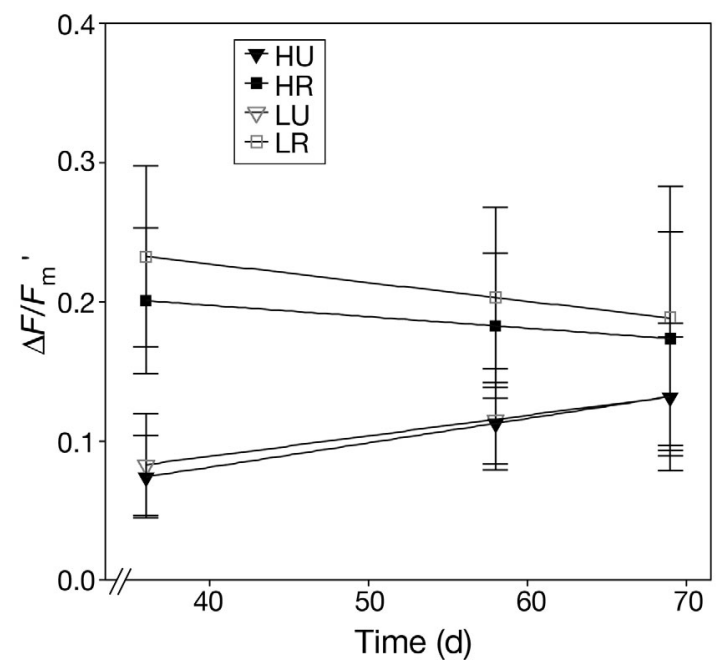

Fig. 3. Effects of species identity and density on photosynthetic efficiency $\left(\Delta F / F_{\mathrm{m}}{ }^{\prime}\right)$. Data are from single species treatments including either Patella ulyssiponensis or Patella rustica at high and low levels of density (corresponding to 6 and 3 animals per plot, respectively). Lines indicate the prototypical trajectories of the temporal trends $(n=4$, fitted means \pm bootstrapped standard deviations obtained by 1000 iterations). HU: high density, P. ulyssiponensis; HR: high density, P. rustica; LU: low density, P. ulyssiponensis; LR: low density, P. rustica

Supplement). In contrast, neither species identity nor species density affected $F_{0}$ during the course of the experiment (Fig. 2; see Table S2 in the Supplement).

At the first sampling date, biofilm photosynthetic efficiency was more than 5 times greater in treatments containing mixtures of P. ulyssiponensis and Porchus turbinatus at high density compared to expected yields from single species treatments (ANOVA on non-transgressive over/underyielding: $F_{1,10}=8.435$, $\mathrm{p}<0.05$; Table 2), and $>29$ times larger than in plots with $P$. ulyssiponensis alone, which was the best performing species (ANOVA on transgressive over/underyielding: $F_{1,6}=6.430, \mathrm{p}<0.05$; Table 2). Similarly, the amount of photosynthetic biomass in treatments containing mixtures of the 3 gastropod species was twice that observed in the best performing single species treatment at high density (i.e. P. turbinatus), resulting in a significant effect on transgressive over/underyielding (ANOVA: $F_{1,6}=8.370, \mathrm{p}<0.05$; Table 2). At the second and third sampling dates, nontransgressive over/underyielding and transgressive over/underyielding values were closer to 0 than those at the first sampling date. However, at the third sampling date, the amount of photosynthetic biomass in treatments containing mixtures of the 3 gastropod species was more than 3 times greater than that observed in the best performing single species treatment
Table 2. Non-transgressive over/underyielding $\left(D_{\mathrm{T}}\right)$ and transgressive over/underyielding $\left(D_{\mathrm{MAX}}\right)$ ratios at the first, second and third sampling dates for photosynthetic efficiency $\left(\Delta F / F_{\mathrm{m}}{ }^{\prime}\right)$ and biomass $\left(F_{0}\right)$. Numbers indicate proportional deviation from expected value. Negative values indicate that mixtures of grazers have a higher grazing efficiency on biofilm than single species treatments, and positive values indicate the opposite. The best performing single species treatment (i.e. the treatment showing the lowest value) is shown in parentheses for photosynthetic efficiency and biomass, respectively. PU, PR and PT stand for Patella ulyssiponensis, Patella rustica and Porchus turbinatus, respectively. Values that deviate significantly from the expected values are indicated in bold

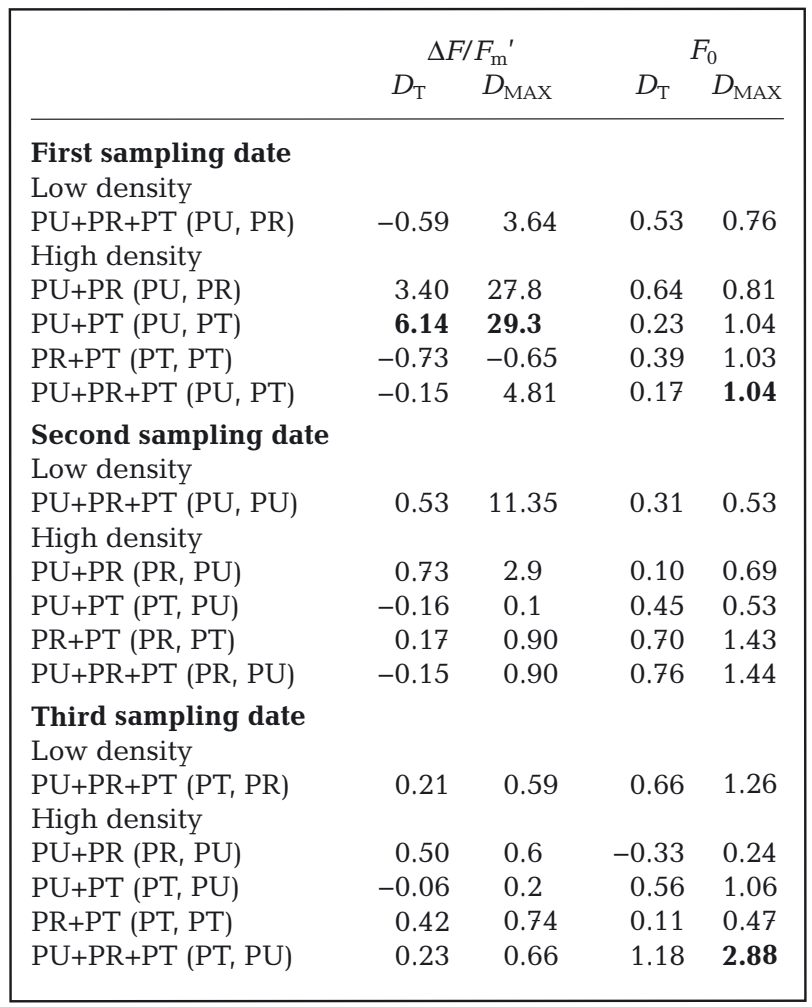

at high density (i.e. P. ulyssiponensis; ANOVA on transgressive over/underyielding: $F_{1,6}=8.712, \mathrm{p}<$ 0.05; Table 2).

No artefacts due to the presence of cages were detected on photosynthetic efficiency or biomass. Significant intercept coefficients of the model of photosynthetic biomass (Table S3 in the Supplement) indicated that the photosynthetic biomass $\left(F_{0}\right)$ in the control treatment was significantly greater than 0 at the first sampling date, and had a significantly decreasing trend during the experiment (Fig. 1B, Table S3 in the Supplement). Biofilm photosynthetic efficiency and biomass did not show significant differences between the control treatment and the treatments with 3 species at both densities (Table S4 in the Supplement). 


\section{DISCUSSION}

Our results show how changes in richness, identity and density of gastropod grazers may have strong, albeit transient, effects on rocky intertidal biofilm. Effects were more evident at the beginning of the experiment, decreasing over time. Our analyses revealed, at the first sampling date, a non-linear relationship between gastropod species richness and photosynthetic efficiency of biofilm, driven by both strong density-dependent identity effects and complementarity, whereas effects on biomass were negligible. Grazing is a main driver of biofilm composition (Skov et al. 2010), and lack of changes in biofilm biomass might underscore compensatory mechanisms where the selective removal of some species may lead to the subsequent growth of others. Although no data on biofilm species composition were available for our experiment, results on both photosynthetic biomass and efficiency of biofilm support the hypothesis of mechanisms of selective removal, driven by density-dependent identity effects.

Single species treatments pointed to significant differences in the effect on biofilm photosynthetic efficiency between Patella ulysisponensis and Patella rustica. Being a generalist herbivore, P. ulyssiponensis consumed all components of biofilm unspecifically. Thus, by further reducing the less abundant taxa, P. ulyssiponensis likely favored the growth of the most competitive species, in this case, cyanobacteria (Kaehler \& Froneman 2002, Norton et al. 1990), resulting in a biofilm assemblage with a low photosynthetic efficiency (Kaehler \& Froneman 2002, Bonnineau et al. 2010). This effect may have occurred at both low and high density, because densitydependent intraspecific competition is generally low among individuals with a generalist diet. In contrast, the specialist $P$. rustica feeds mostly on cyanobacteria (Della Santina et al. 1993), likely facilitating the growth of the less competitive, but more efficient biofilm components. This effect was less evident at high abundance of $P$. rustica, possibly due to densitydependent intraspecific competition, which is more likely to occur with specialist than with generalist species (Minot 1981). The topshell Porchus turbinatus is a generalist grazer; however, by removing detritus (Alyakrinskaya 2010), it might have increased the photosynthetic efficiency of all of the biofilm species (Skov et al. 2010), thus resulting in larger values than those in the treatments comprising only P. ulyssiponensis. Herbivores can be either generalists or specialists and display different strategies to acquire foodi as a consequence, loss of species at the consumer level is more likely to produce idiosyncratic responses in ecosystem functioning compared to losses at the producer level (Hooper et al. 2005).

Contrary to our expectation, the higher photosynthetic efficiency in 2-species compared to 1-species treatments may reflect complementarity in herbivores' resource use. In particular, in the treatment comprising $P$. ulyssiponensis and $P$. turbinatus, cyanobacteria likely dominated due to the presence of 2 generalist grazers, but their low photosynthetic efficiency could have been largely facilitated by the removal of detritus by P. turbinatus (Skov et al. 2010). Differently, when $P$. ulyssiponensis was present with the more specialist species $P$. rustica, it is possible that a large amount of cyanobacteria was removed, leading to a subsequent dominance of more efficient biofilm than when only P. ulyssiponensis was present. When all 3 herbivore species were present, the grazing pressure was generally weaker than with 2 species, because the relative densities of herbivores (in particular the specialist herbivore) were lower than in the 2-species treatments. This could be the reason why, in these treatments, we did not observe large changes compared to the naturally occurring dominance of the less efficient biofilm species (i.e. cyanobacteria). This finally resulted in a non-linear effect of grazer richness on photosynthetic efficiency of biofilm.

Although the effects of grazer diversity on biofilm biomass were negligible, it is worth stressing the role of $P$. turbinatus at the first time of sampling. In contrast to slow-moving limpets, the topshell $P$. turbinatus is an active and mobile grazer (Alyakrinskaya 2010). At high density (i.e. 6 individuals per species), the consumption rate of $P$. turbinatus was probably too high to be compensated by the growth of biofilm. Thus, biofilm biomass was significantly lower than in the 3-species treatment, where relative densities were the lowest (i.e. 2 ind. per species). Therefore, more than competitive mechanisms, the significantly higher biofilm biomass in the 3 -species treatment in comparison to the treatment with $P$. turbinatus alone highlighted a density-dependent negative effect of $P$. turbinatus on biofilm biomass removal. Densitydependent effects can be influential in BEF relationships (Griffin et al. 2008), modifying the role of either complementarity or identity effects. Results from the present study further highlighted the need for explicitly including density of organisms as a manipulated factor within BEF experimental designs (BenedettiCecchi 2004).

Our analysis revealed a decline in biomass during the course of the experiment, from winter to spring, 
independently of grazing. The tendency for biomass to decrease as insolation increases is in agreement with studies conducted in other regions (Castenholz 1961, Underwood 1984, Thompson et al. 2004). Interestingly, differences among treatments decreased during the course of the experiment, and this happened for both photosynthetic efficiency and biomass. Photosynthetic efficiency, however, showed an opposite, albeit not significant, temporal trend to that displayed by biomass, increasing rather than decreasing through time. This could indicate a modification in biofilm composition, towards species with higher photosynthetic efficiency, such as diatoms and green algae (Kaehler \& Froneman 2002, Bonnineau et al. 2010). The reduced impact of grazers observed for this variable suggests that grazing efficiency also decreased as time progressed. This is in agreement with a previous study indicating that the foraging activity of limpets is lower in spring compared to fall and winter in the Mediterranean (Della Santina \& Chelazzi 1991). Another study has shown temporally variable effects of biodiversity on ecosystem functioning (O'Connor \& Crowe 2005), underlying the need for BEF studies encompassing relatively long intervals of time with respect to species' life history.

Although the lack of repetition of this experiment would prevent us from assessing temporal consistency (or lack thereof) of our results, the short lifespan of microphytobenthic organisms makes us confident that the duration of the experiment was appropriate to evaluate the effects of biodiversity on biofilm. In particular, the experiment encompassed a relatively wide range of microphytobenthic biomass. We would therefore generally expect a more pronounced effect of grazer biodiversity at high microphytobenthic biomass values, weakening at decreasing biomass levels.

Diversity effects are supposed to be stronger for trophic levels comprising species with different specializations, as this allows for complementary diets (Finke \& Snyder 2008, Snyder et al. 2008). A recent investigation also highlighted how effects on ecosystem multifunctionality were stronger for herbivore than for plant biodiversity (Lefcheck et al. 2015). However, it is difficult to find general rules linking food web to ecosystem functioning, and this remains an open area of research (O'Connor \& Byrnes 2013). Our study highlighted how heterogeneity in species identity can result in negligible effects on producer biomass, while driving significant changes in photosynthetic efficiency of fast-growing primary producers. In particular, changes in richness and/or identity of grazers may result in density-dependent mecha- nisms of complementarity or competition for resources, which translate to the selective removal of some primary producers and subsequent increase in others. Despite no changes in overall biomass, differences in physiological (i.e. photosynthetic) and ecological traits of prey species can then lead to changes in overall efficiency of primary producer assemblages.

In conclusion, when making predictions about the consequences of changes in biodiversity of consumers on their prey, both ecological (e.g. feeding characteristics, competitive abilities) and physiological traits (e.g. metabolic, photosynthetic efficiency) of species should be taken into account. By explicitly modifying the abundance of consumers in BEF experimental designs, density-dependent mechanisms of complementarity or competition can be revealed. This approach allowed us to explain unexpected effects of consumers on biofilm ecosystem functions in terms of the alternating prevalence of resource partitioning versus density-dependent mechanisms of competition among specific assemblages.

Acknowledgements. We are grateful to Laura Tamburello for her help in the field. C.S.L. was supported by a postdoctoral grant from the Alfonso Martin Escudero Foundation from Spain. This work was partially supported by the University of Pisa.

\section{LITERATURE CITED}

Alyakrinskaya IO (2010) Some adaptations of Monodonta turbinata (Born, 1780) (Gastropoda, Prosobranchia, Trochidae) to feeding and habitation in the littoral zone. Biol Bull 37:63-68

> Aquilino KM, Stachowicz JJ (2012) Seaweed richness and herbivory increase rate of community recovery from disturbance. Ecology 93:879-890

Atalah J, Crowe TP (2012) Nutrient enrichment and variation in community structure on rocky shores: the potential of molluscan assemblages for biomonitoring. Estuar Coast Shelf Sci 99:162-170

Barranguet C, Kromkamp J (2000) Estimating primary production rates from photosynthetic electron transport in estuarine microphytobenthos. Mar Ecol Prog Ser 204: 39-52

Benedetti-Cecchi L (2000) Predicting direct and indirect interactions during succession in a mid-littoral rocky shore assemblage. Ecol Monogr 70:45-72

Benedetti-Cecchi L (2004) Increasing accuracy of causal inference in experimental analyses of biodiversity. Funct Ecol 18:761-768

Benedetti-Cecchi L (2006) Understanding the consequences of changing biodiversity on rocky shores: how much have we learned from past experiments? J Exp Mar Biol Ecol 338:193-204

Bonnineau C, Guasch H, Proia L, Ricart M, Geiszinger A, Romani AM, Sabater S (2010) Fluvial biofilms: a perti- 
nent tool to assess beta-blockers toxicity. Aquat Toxicol 96:225-233

- Bracken MES, Williams SL (2013) Realistic changes in seaweed biodiversity affect multiple ecosystem functions on a rocky shore. Ecology 94:1944-1954

Bracken MES, Friberg SE, Gonzalez-Dorantes CA, Williams SL (2008) Functional consequences of realistic biodiversity changes in a marine ecosystem. Proc Natl Acad Sci USA 105:924-928

- Butchart SHM, Walpole M, Collen B, van Strien A and others (2010) Global biodiversity: indicators of recent declines. Science 328:1164-1168

- Castenholz RW (1961) The effect of grazing on marine littoral diatom populations. Ecology 42:783-794

> Christofoletti RA, Almeida TVV, Ciotti AM (2011) Environmental and grazing influence on spatial variability of intertidal biofilm on subtropical rocky shores. Mar Ecol Prog Ser 424:15-23

Coll M, Piroddi C, Steenbeek J, Kaschner K and others (2010) The biodiversity of the Mediterranean Sea: estimates, patterns, and threats. PLoS ONE 5:e11842

> Dal Bello M, Maggi E, Rindi L, Capocchi A, Fontanini D, Sanz-Lázaro C, Benedetti-Cecchi L (2015) Multifractal spatial distribution of epilithic microphytobenthos on a Mediterranean rocky shore. Oikos 124:477-485

> Della Santina P, Chelazzi G (1991) Temporal organization of foraging in two Mediterranean limpets, Patella rustica L. and P. coerulea L. J Exp Mar Biol Ecol 153:75-85

Della Santina P, Sonni C, Sartoni G, Chelazzi G (1993) Food availability and diet composition of three coexisting Mediterranean limpets (Patella spp.). Mar Biol 116:87-95

Duffy JE, Macdonald KS, Rhode JM, Parker JD (2001) Grazer diversity, functional redundancy, and productivity in seagrass beds: an experimental test. Ecology 82 : 2417-2434

Emmerson M, Huxham M (2002) How can marine ecology contribute to the biodiversity-ecosystem functioning debate? In: Loreau M, Naeem S, Inchausti P (eds) Biodiversity and ecosystem functioning: synthesis and perspectives. Oxford University Press, Oxford, p 139-146

- Finke DL, Snyder WE (2008) Niche partitioning increases resource exploitation by diverse communities. Science 321:1488-1490

Gable JT, Crowder DW, Northfield TD, Steffan SA, Snyder WE (2012) Niche engineering reveals complementary resource use. Ecology 93:1994-2000

Gamfeldt L, Lefcheck JS, Byrnes JEK, Cardinale BJ, Duffy JE, Griffin JN (2015) Marine biodiversity and ecosystem functioning: what's known and what's next? Oikos 124: 252-265

> Golléty C, Crowe TP (2013) Contribution of biofilm to ecosystem functioning in rock pools with different macroalgal assemblages. Mar Ecol Prog Ser 482:69-79

Griffin JN, De la Haye KL, Hawkins SJ, Thompson RC, Jenkins SR (2008) Predator diversity and ecosystem functioning: density modifies the effect of resource partitioning. Ecology 89:298-305

Griffin JN, Noel LMLJ, Crowe TP, Burrows MT, Hawkins SJ, Thompson RC, Jenkins SR (2010) Consumer effects on ecosystem functioning in rock pools: roles of species richness and composition. Mar Ecol Prog Ser 420:45-56

Hawkins SJ, Sugden HE, Mieszkowska N, Moore PJ and others (2009) Consequences of climate-driven biodiversity changes for ecosystem functioning of North European rocky shores. Mar Ecol Prog Ser 396:245-259
Hector A, Schmid B, Beierkuhnlein C, Caldeira MC and others (1999) Plant diversity and productivity experiments in European grasslands. Science 286:1123-1127

Helmuth B, Mieszkowska N, Moore P, Hawkins SJ (2006) Living on the edge of two changing worlds: forecasting the responses of rocky intertidal ecosystems to climate change. Annu Rev Ecol Evol Syst 37:373-404

- Honeywill C, Paterson DN, Hagerthey SE (2002) Determination of microphytobenthic biomass using pulseamplitude modulated minimum fluorescence. Eur J Phycol 37:485-492

$>$ Hooper DU, Chapin FS, Ewel JJ, Hector A and others (2005) Effects of biodiversity on ecosystem functioning: a consensus of current knowledge. Ecol Monogr 75:3-35

> Hooper DU, Adair EC, Cardinale BJ, Byrnes JEK and others (2012) A global synthesis reveals biodiversity loss as a major driver of ecosystem change. Nature 486: 105-108

Jesus B, Perkins RG, Consalvey M, Brotas V, Paterson DM (2006) Effects of vertical migrations by benthic microalgae on fluorescence measurements of photophysiology. Mar Ecol Prog Ser 315:55-66

> Kaehler S, Froneman PW (2002) Herbivore-mediated increase in the photosynthetic capacity of marine biofilms: indirect effects of changing microalgal assemblage composition. Mar Ecol Prog Ser 234:15-22

Lefcheck JS, Byrnes JEK, Isbell F, Gamfeldt L and others (2015) Biodiversity enhances ecosystem multifunctionality across trophic levels and habitats. Nature Commun 6: 6936

Logan BA, Adams WW, Demmig-Adams B (2007) Avoiding common pitfalls of chlorophyll fluorescence analysis under field conditions. Funct Plant Biol 34:853-859

Loreau M (1998) Separating sampling and other effects in biodiversity experiments. Oikos 82:600-602

Loreau M, Hector A (2001) Partitioning selection and complementarity in biodiversity experiments. Nature 412: 72-76

Maggi E, Jackson AC, Tolhurst T, Underwood AJ, Chapman MG (2013) Changes in microphytobenthos fluorescence over a tidal cycle: implications for sampling designs. Hydrobiologia 701:301-312

> Matthiessen B, Gamfeldt L, Jonsson PR, Hillebrand H (2007) Effects of grazer richness and composition on algal biomass in a closed and open marine system. Ecology 88: 178-187

Millennium Ecosystem Assessment (2005) Ecosystems and human well-being: synthesis. Island Press, Washington, DC

> Minot EO (1981) Effects of interspecific competition for food in breeding blue and great tits. J Anim Ecol 50:375-385

Norton TA, Hawkins SJ, Manley NL, Williams GA, Watson DC (1990) Scraping a living - a review of littorinid grazing. Hydrobiologia 193:117-138

O'Connor MI, Byrnes JEK (2013) Biodiversity and ecosystem function: Does pattern influence process? In: Bertness MD, Silliman BR, Bruno JF, Stachowicz JJ (eds) Marine community ecology and conservation. Sinauer, Sunderland, MA, p 109-130

O'Connor NE, Crowe TP (2005) Biodiversity loss and ecosystem functioning: distinguishing between number and identity of species. Ecology 86:1783-1796

> Purvis A, Gittleman JL, Cowlishaw G, Mace GM (2000) Predicting extinction risk in declining species. Proc R Soc B 267:1947-1952 
R Development Core Team (2012) R: a language and environment for statistical computing, reference index version 2.15.0. R Foundation for Statistical Computing, Vienna, Austria

Raffaelli D, Hawkins SJ (1996) Intertidal ecology. Chapman \& Hall, London

Schreiber U (2004) Pulse-amplitude-modulation (PAM) fluorometry and saturation pulse method: an overview. In: Papageorgiou GC, Govindjee (eds) Chlorophyll a fluorescence: a signature of photosynthesis. Springer, Dordrecht, p 279-319

Singer JD, Willet JB (2003) Applied longitudinal data analysis: modeling change and event occurrence. Oxford University Press, New York, NY

Skov MW, Volkelt-Igoe M, Hawkins SJ, Jesus B, Thompson RC, Doncaster CP (2010) Past and present grazing boosts the photo-autotrophic biomass of biofilms. Mar Ecol Prog Ser 401:101-111

Snyder GB, Finke DL, Snyder WE (2008) Predator biodiversity strengthens aphid suppression across single- and multiple-species prey communities. Biol Control 44:52-60

Solan M, Aspden RJA, Paterson DM (2012) Marine biodiversity futures and ecosystem functioning: frameworks, methodologies and integration. Oxford University Press, Oxford

Editorial responsibility: Pei-Yuan Qian, Kowloon, Hong Kong SAR
Stachowicz JJ, Bruno JF, Duffy JE (2007) Understanding the effects of marine biodiversity on communities and ecosystems. Annu Rev Ecol Evol Syst 38:739-766

> Thompson RC, Roberts MF, Norton TA, Hawkins SJ (2000) Feast or famine for intertidal grazing molluscs: a mismatch between seasonal variations in grazing intensity and the abundance of microbial resources. Hydrobiologia 440:357-367

Thompson RC, Crowe TP, Hawkins SJ (2002) Rocky intertidal communities: past environmental changes, present status and predictions for the next 25 years. Environ Conserv 29:168-191

Thompson RC, Norton TA, Hawkins SJ (2004) Physical stress and biological control regulate the producerconsumer balance in intertidal biofilms. Ecology 85: 1372-1382

Underwood AJ (1984) Vertical and seasonal patterns in competition for microalgae between intertidal gastropods. Oecologia 64:211-222

Underwood AJ (1997) Experiments in ecology: their logical design and interpretation using analysis of variance. Cambridge University Press, Cambridge

Wahl M (1989) Marine epibiosis. I. Fouling and antifouling: some basic aspects. Mar Ecol Prog Ser 58: 175-189

Submitted: February 2, 2015; Accepted: October 2, 2015 Proofs received from author(s): November 14, 2015 